\title{
STUDIOGO AND THE IMPORTANCE OF USER-CENTRED DESIGN
}

\author{
by
}

\section{Christian Bebis}

Bachelor of Arts, Brock University, October 2017

\author{
A Major Research Project \\ presented to Ryerson University \\ in partial fulfillment of the \\ requirements for the degree of \\ Master of Digital Media \\ in the program of Digital Media
}

Toronto, Ontario, Canada, 2019

(C) Christian Bebis, 2019 


\section{AUTHOR'S DECLARATION FOR ELECTRONIC SUBMISSION OF MRP}

I hereby declare that I am the sole author of this MRP. This is a true copy of the MRP, including any required final revisions.

I authorize Ryerson University to lend this MRP to other institutions or individuals for the purpose of scholarly research

I further authorize Ryerson University to reproduce this MRP by photocopying or by other means, in total or in part, at the request of other institutions or individuals for the purpose of scholarly research.

I understand that my MRP may be made electronically available to the public. 


\title{
STUDIOGO \& THE IMPORTANCE OF USER-CENTRED DESIGN
}

Master of Digital Media

Digital Media

Christian Bebis

Ryerson University, 2019

\begin{abstract}
In helping creative students and professionals find nearby spaces that are conducive to them working on their projects and crafts, I have shown how the Stanford Design Thinking model can be used to help empathize, design, ideate and prototype a mobile application. This design thinking model has been applied to solve a set of common problems for creatives, which are finding adequate workspaces, while creating and maintaining connections with others in their field. This paper will allow readers insight to the design thinking process and will attempt to contribute to a greater understanding of the methodology while attempting to create a solution that best fits the needs of the creative community.
\end{abstract}

Keywords: creative, design thinking, studiogo, creative workspaces, crowdsourcing, user interface design 


\section{Dedication}

Dedicated to my mom. 


\section{Table of Contents}

$\begin{array}{ll}\text { Author's Declaration } & \text { ii }\end{array}$

Abstract

Dedication $\quad$ iv

Table of Contents $\quad$ V

Introduction 1

$\begin{array}{ll}\text { Stanford Design Thinking Model } & 7\end{array}$

Problems \& Pains Creatives Believe They Suffer 99

Literature Review

Design 2

$\begin{array}{ll}\text { Crowdsourcing } & 4\end{array}$

Suitable Spaces \& Creative Environments $\quad 5$

$\begin{array}{ll}\text { Introduction to the Design Thinking } & 7\end{array}$

$\begin{array}{ll}\text { Empathize } & 8\end{array}$

$\begin{array}{ll}\text { Define } & 9\end{array}$

$\begin{array}{ll}\text { Ideate } & 10\end{array}$

$\begin{array}{ll}\text { StudioGo } & 11\end{array}$

Prototype and Test 12

StudioGo Prototype Version \#1 13

StudioGo Version \#1 Test 14

StudioGo Prototype Version \#2 15

StudioGo Version \#2 Test 16

$\begin{array}{ll}\text { StudioGo Version \#3 Prototype } & 17\end{array}$

$\begin{array}{ll}\text { StudioGo Version \#3 Test } & 18\end{array}$

StudioGo Version \#4 Prototype (Final Prototype) 19

$\begin{array}{ll}\text { Conclusion } & 20\end{array}$

$\begin{array}{ll}\text { References } & 22\end{array}$ 


\section{StudioGo and The Importance of User-Centred Design}

\section{Introduction}

The arts are the wild west of any modern-day profession. The umbrella term refers to writers, photographers, painters, graphic designers, poets, musicians, dancers, actors, and much more. With all this diversity among such talented people, there are challenges in creating a cohesive community. Throughout this paper, we will take a deep dive into the problems that creative people experience when working on their craft. I will be an attempt to create a solution that addresses one of the challenges faced by creatives: how to locate nearby appropriate workspaces that are conducive to them and their work. Currently, there exists no dedicated platform or service that cohesively solves this. Using the Stanford design thinking methodology, this paper will attempt to find a solution for creatives to discover appropriate workspaces and connect with the greater creative community.

\section{Literature Review}

Before diving into the Stanford design methodology, three key elements need to be discussed in relation to creative people and their needs. As stated, creatives have problems in a couple key areas, including finding suitable workspaces for their creative needs and connecting with others in their craft, whether it is to collaborate or learn from each other. This literature review will look at various works to understand design and its relation to the Stanford design thinking methodology, how creatives thrive in different environments, the importance of crowdsourced environments and the impact of tailored spaces on creatives. 


\section{Design}

Design thinking is not about solving any problem, it is about solving the correct problem based on the feedback from your user base. So, how do user experience (UX) designers do this? "Good designers never start by trying to solve the problem given to them: they start by trying to understand what the real issues are. A brilliant solution to the wrong problem can be worse than no solution at all: solve the correct problem." (Norman, 2013). These are the words of Don Norman from his book The Design of Everyday Things. His point of view is seen by many as the backbone of the design thinking process. This is about designing with the user and not for the user. This is the essence of user-centered design.

It is important to keep the user involved in all steps of the development process. Norman asks us to think about how designers create their solutions. First a problem must be articulated. This expression of a potential problem is known as a suggestion - not the final statement. Once the suggestion is made, designers can speak with users to determine whether this is a problem in need of a solution. If so, the designer must proceed with caution, so an intended solution is not made prematurely. This is the beginning of the process known as the Stanford method. It's central premise is that everything starts with, and ends with, the user.

Usability testing is a key pillar of the Stanford method. The method flips the narrative of the standard product development process, allowing the end-user to help in the creation of a product, thereby letting it be changed and altered to suit the needs of those who need it most. This is exactly what we're trying to do in this research project.

Creatives have particular needs, and it is the job of the UX designer to help meet those needs. In Don't Make Me Think, Steve Krug provides an understanding of the UX and the 
development of the entire process that the Stanford method spells out. The book provides an indepth overview on how to approach mobile and web usability. The most important piece from this publication as it relates to the user experience, is how it speaks about the usability test. Krug believes it is important to test not only users in your user segment, but also the generic user. Krug attempts to explain that if you are designing for a specific brand of user you cannot expand your horizons later. He goes on to say;

"It is usually not a good idea to design a site so that only your target audience can use it. Domain knowledge it a tricky thing and if you design a site for money managers using terminology that you think all money managers will understand, what you'll discover is that a small but not insignificant number of them won't know what you're talking about" (Krug, 2014).

Design plays a crucial role in the process of creating a solution that best fits the needs of the user, but if done poorly, it can instead have a negative effect that will cause users to shun it. There is a balance between a specialized solution that can play a positive role in a person's day-to-day work, which is different from a solution that is only meant for a very specific type of person. It is important to design for your target market, but just as important to allow growth into other areas.

Before creating a viable solution, it must be understood that there is a type of product that is needed to allow users to succeed. In The Best Interface is No Interface, Golden Krishna, looks at user-centered design and whether a screen-based product is the best thing to use when creating a solution for certain groups of people. Krishna speaks about the difference in user experience and the user interface. It is important to understand that they do not equal each other, and many companies get confused with this. Krishna states:

"Somewhere along the way, we confused the two. And instead of pursuing the best, most creative, inventive and useful ways to solve a problem, we started solving problems with screens because that was our job description. When we saw problems, we slapped an interface on it. UX stopped being about the people and started being about rounded rectangles and parallax animations." (Krishna, 2015) 
This is extremely important when attempting to use the design thinking methodology. If focused on just the design of a product, especially a screen-based product without any understanding that you are solving a problem for a group of individuals, you lose sight of the impact on the people that you are trying to help. That is why user experience design is so important. It provides not only a gratifying experience for the designer, it can also go a long way in helping the people who need it most. It is not only about design, but about the entire process of the Stanford design methodology.

\section{Crowdsourcing}

When trying to help solve a problem for a group of people, why not also have them aid in the process of finding a solution? Crowdsourcing is a unique way to allow the user to be involved in the process of solving a problem that can help all users. Crowdsourcing "involves the harnessing of the collective knowledge and intelligence of a large number of individuals to generate solutions to relatively complex problems" (Davis \& Rahmanian, 2014). This is an intriguing notion, because it allows the end user to drive the entire design process. Who better to understand what's required in their space than the users themselves. This is important because now the user has become a part of the solution. The article by Davis and Rahmanian (2014) does continue to explore the importance of crowdsourcing as it is important to understand that the user interface will play a large role in the way users share and use the data collected. "Unnecessary distracting features and high number of clicks put more cognitive load on the task and tend to poor results from users" (Davis \& Rahmanian, 2014). If the design suffers so will the results. This is something that needs to be looked at when trying to develop a crowdsourced system. If there are external factors that may impact a result, the end result may create more problems for the end user than it is trying to solve. 
In turn, quality control becomes a major issue for crowdsourcing systems. In Mohaammad Allahbakhsh, et al. (2013) article they attempt to understand the issues within the quality control of crowdsourcing systems. "Quality is a subjective issue in general. Some efforts have proposed models and metrics to quantitatively and objectively assess quality along different dimensions of a software system, such as reliability, accuracy, relevancy, completeness, and consistency" (Allahbakhsh, et al., 2013). To gain a greater understanding of the above metrics the article looks at the reputation, expertise \& the design of the user interface (as mentioned previously). All of which impact the input from users in a crowdsourced system. Allahbakhsh, et al. (2013) understand that the relationship between the requester and the worker is an important dynamic, but there needs to be a level of expertise from these users by providing credentials that provide evidence that the user has the knowledge that would be useful for the rest of the crowdsourced community. Though there is an understanding of these systems it is believed that "although researchers have proposed and used several quality control approaches so far, many open issues and challenges remain for defining, measuring, and managing quality in crowdsourcing systems, and these issues require further research and investigation" (Allahbakhsh, et al., 2013).

\section{Suitable Spaces \& Creative Environments}

In Creative environments for design education and practice, Katja Thoring (2018) writes that there are five space variations that can have an impact on the work that a creative can produce:

1. Personal space that allows for a solo concentrated workflow.

2. Collaboration space, which is used for group projects.

3. Presentation space, which is used to share ideas.

4. Making space, which could be considered another variation of the collaboration space, but with the tools to help creatives build and experiment. 
5. Intermission space to get away from your work. A place for thought and relaxation.

Thoring (2018) says these five space variations enhance and change the type of work a creative produces based entirely and exclusively on their working environment. Thoring says "space can act as a source of simulation by providing noise, smell, views, colours, and textures; by displaying inspirational posters; or by providing games and gadgets. A space may also trigger creativity by reducing stimulation." (Thoring, 2018). She suggests a balance among these different environments is important in creating a smooth workflow, especially for those in the creative fields.

Donatella De Paoli \& Arja Ropo (2017) continue the conversation about creative spaces and their impacts, but they discuss the phenomenon insofar as they question the sustainability of these spaces. In the article Creative workspaces - a fad of making real impact? De Paoli \& Ropo concluded, (Similar to Thoring), that:

"organizational creativity needs both individual enclosed spaces as well as open, transparent and collaborative spaces. Our second proposition claims that workspaces may be particularly designed for ... creativity to emerge. We also propose that beyond spaces, creative processes also need various types of material tools. (Paoli \& Ropo, 2017).

De Paoli \& Ropo describe the same workspaces in which Thoring introduced in her article. This provides an understanding that creative workspaces are not just faddish, but intrinsic and essential to the production of creative output.

De Paoli \& Ropo (2017) extend Thoring's argument by bringing in the end user. They say the end user should be an equal partner in the design of creative workspaces. This conception of the end user dovetails into the understanding of Stanford method, and the user's impact in the creation of a solution that best fits their needs. 


\section{Introduction to the Design Thinking}

Stanford Design Thinking Method - Figure 1.
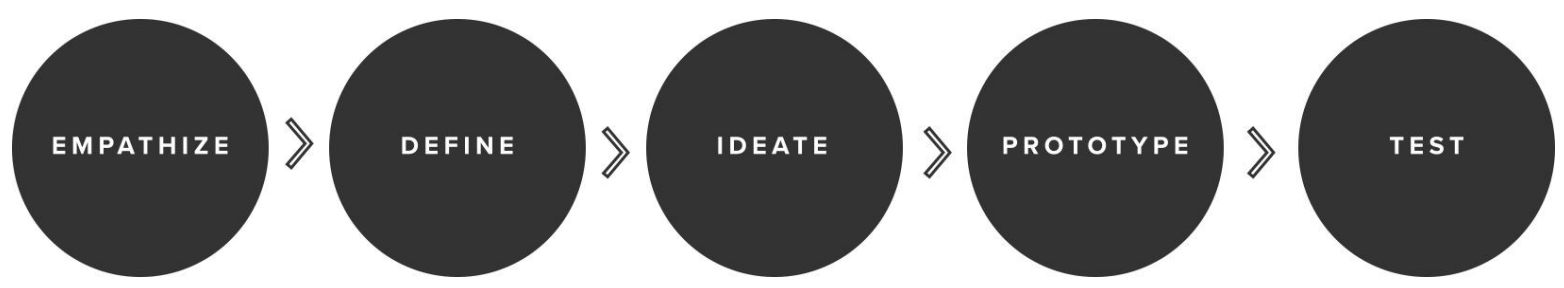

This major research project will continue to focus on the UX design process known as the Stanford design thinking methodology. The Stanford methodology focuses on creative problem solving in five different steps. This includes empathize, define, ideate, prototype $\&$ test. There is no order or concrete completion to this method, as it was created in order to ideate and reiterate as new problems arise. We have found that creatives have trouble finding adequate and affordable workspaces to work on their craft whatever that craft may be: graphic design, painting, music, writing, woodworking, etc. Throughout this paper, drawing on the principles of the Stanford method, there will be a focus on understanding creatives and if there are any problems that need to be solved using the five major steps from the Stanford method. The first step is to empathize with the user. The initial empathy step includes understanding who the user is, what their motives are and if they have any problems achieving their goals within their profession. This portion of the methodology is to see if the initial suggestion accurately represents your user by letting them tell you more about themselves. When it is time to define, you are looking to have a greater understanding of the problem in an attempt to solve it. You do this by taking the information provided in the previous steps and creating a concise statement that can be worked with. The ideation phase is where solutions begin to take shape. This is the time where you take the problems that were identified in the define phase and begin to visual how it could be solved. From this point on you begin to prototype your solution and test it on the 
users that you spoke with throughout the process. It is not only important to talk with your users during the empathize phase, but to also keep them in touch throughout all phases of the design thinking process because as things develop the user may provide more data that can help as a solution is created. After testing you will continue to make changes and talk with the users to see how it can improve or change. This is a never-ending process in the hunt to create a solution that can help all users that experience the problem and help create the best solution for them.

\section{Empathize}

From September of 2018 to July of 2019 , over 40 users were interviewed to understand the problems that creatives have. The initial suggestion based on experience in the creative industry included the ability to find adequate workspaces for photographic work in the creative arts. Based on this suggestion, there was a decision made to not ask questions that would lead our users to the same conclusions that have already been considered. Questions that were asked during this phase included:

(1) Would you describe yourself as a creative student?

(2) How do you dream of having a top-level career in the creative industry;

(3) Are there any obstacles in achieving that? If so, what are they?

From this point of the interview there would be a good sense of whether the person being interviewed had any significant problems in their field. After completing the first batch of interviews it was understood that creatives faced two major problems. The first of which confirmed the suggestion that creatives do have trouble finding workspaces to work on artistic endeavours. The surprising second problem being that many felt that they did not have the ability to connect with other artists in the industry. Many stating that they did not have much collaboration with others within their field and were looking for other that could speak the same creative language as them. 


\section{Define}

Once the interviews were completed, there was an attempt to create a problem statement based on our findings. The findings proved that our initial assumption was correct. Creative students have a difficult time finding adequate workspaces to work on their creative endeavours. $24.6 \%$ of people mentioned this a major problem. The number which we did not see coming was the amount of people that had a problem making connections within their own industry. This was a staggering $29.5 \%$ of people. There were a variety of issues that creatives had mentioned, but these were clearly the front runners. With this understanding there needs to be a way to combine the two problems that would allow the user to manage these problems with ease.

Problems \& Pains Creatives Believe They Suffer - Figure 2.

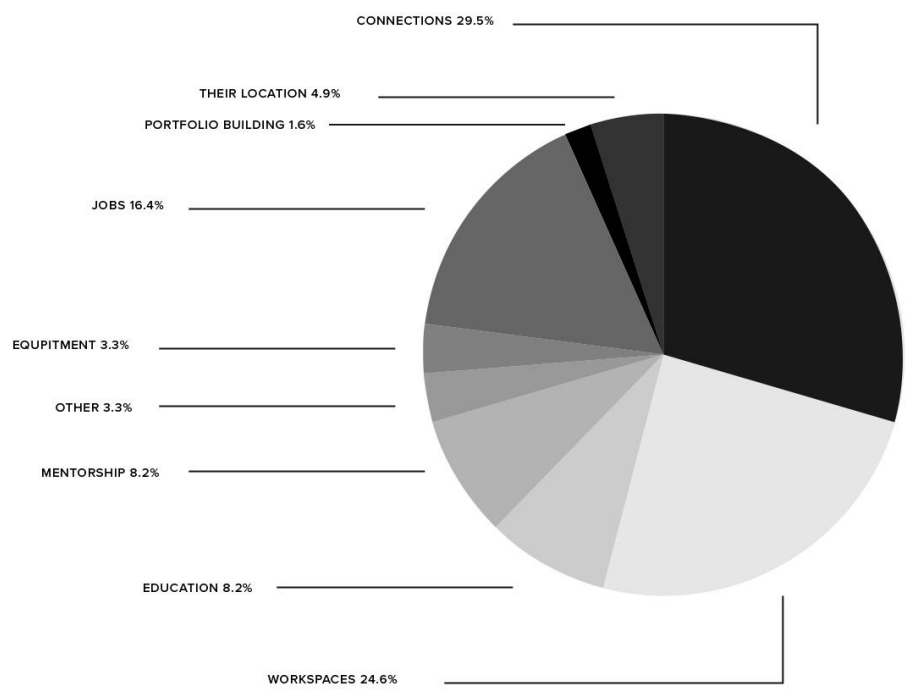

Based on these findings the problem statement was worded as follows:

"Creatives need help finding adequate and affordable workspaces, while being able to connect with their peers.” (Bebis \& Hopkins, 2019) 
Through interviews with potential users the statement above was created to allow ourselves to dial into the main problems which were expressed during the empathize phase. The mission now becomes: "How do we create something that will help the creative community find appropriate workspaces and connect with the greater creative community?" (Bebis \& Hopkins, 2019). These are the problems; it is now time to come up with a solution.

\section{Ideate}

The problems that our users have are now defined. We know that users have trouble finding workspaces and creating connections with others in their industry. After reading both Golden Krishna's The Best Interface is no Interface (2015) \& Steve Krug's Don't Make Me Think (2014) there was a decision to make the solution screen-based. There is a reason to this madness though. The problems that were described above include the fact that creatives can not find adequate workspaces for their craft. This means that there needs to be an accessible way for the user to find workspaces more conveniently and quickly than they previously could. To understand this idea, applications such as Uber, Airbnb, WeWork, ThisOpenSpace \& Breather were brought to the table to see how they can connect users to spaces \& what their audiences are. After doing research on a few of their organizations we noticed that both WeWork \& Breather are creating applications to connect people with spaces for a variety of work. The only issue is that these locations are not specifically tailored to users that need spaces for creative work. WeWork "provides shared workspaces for technology Startup subculture communities, and services for entrepreneurs, freelancers, start-ups, small businesses and large enterprises" (WeWork, 2019). This is not tailored to the community that problems are trying to be solved for in our user segment. As understood in the Katja Thoring journal, there are specific workspaces that are needed to allow creatives to thrive in their craft. WeWork focuses on a single type of 
space that does not have the necessary tools such as a "Making Space" (Thoring, 2018) or the privacy of a "Personal Space" (Thoring, 2018). There needs to be a solution that is tailored to feature spaces such as these and information that can allow users to focus their search on a specific space they need for their craft. On the other hand, Breather does allow for more tailored spaces that are described in Thoring's (2018) article, but is limited by their search. Airbnb is mainly made up of residential condo, homes \& offices. These spaces themselves do not provide any creative value to them. These are strictly workspaces that are tailored for the customer to mimic the modern office space with the flexibility to be rented up to the hour. Again, this is another application that does not offer the five types of creative spaces to help those in the creative arts thrive.

Now, with this understanding on how a variety of space sharing and renting application work, how can it change to introduce creative spaces into the fold? Is there a way for creatives to easily find the spaces they are looking for? Many of these applications have a larger company telling the user segment what locations they should be looking to rent, when sometimes the application does not actually know what the user wants. What if there was a system that would allow users to help each other to find what they are looking for? A peer system that allows the people who know the most about their area to help others find what they are looking for. A peerto-peer location scouter for creatives. This is StudioGo.

\section{StudioGo}

After looking at companies such as WeWork \& Breather that are attempting to connect their users with a type of space, the decision was made to create a peer system that allows users to find adequate workspaces for their craft. This gives users the ability to find the tailored workspaces that match what they are trying to accomplish while also having the ability to 
connect with others that are trying to do the same thing. With this information in mind StudioGo is: "An application for creative professionals to share their creative insights in a peer-led community, with information on a variety of nearby spaces to suit their creative needs. StudioGo is your in-pocket location scouter" (Bebis \& Hopkins, 2019).

Based on all the information received during the empathize stage this understanding of the user quickly turned into a project about eliminating or at the very least managing a problem that would help these users in their field. There are no ulterior motives here. This is a project solely about helping others. StudioGo is a reaction to the creative community that it is built for. When a product is being built for an entire community, it is best to use the resources of the community to create a new and innovative way to help these people thrive like never before. Just as it is important to understand the user and their craft, it is also important to have a sense of how a solution of this magnitude would be built and how it will be distributed in the future.

\section{Prototype and Test}

A mobile application is the modern-day messiah for the average person. Though a screenbased solution may not always be the way to go about solving a problem, this application is meant for a certain user segment that always needs to have locations accessible. Every person is

different, but there needs to be a common element, in this case, the user interface. Krishna (2015) understands this in his book by arguing that even though every person is different "We don't make a separate digital interface for each and every unique person. Within the constraints for modern front-end software development, that would be an endless, gargantuan task" (Krishna, 2015). Though StudioGo is attempting to satisfy the creative audience, there must be respect paid to both those in the creative arts and the everyday user who may adapt an application such as this to their own craft that may fall outside the realm of the creative. 
Before we get into the application design itself it is important to know that only a few featured pages will be showcased in this paper. For a view of the entire user interface please visit the Adobe XD link in the bibliography. The pages that will be featured in this paper include the (1) map page. This is page also doubles as the home page. This is the first page a user will see when they enter the application. The second page is known as the (2) location information page. This page allows users more in depth information on the location selected from the map page. The third and final page to be discussed is the (3) profile page. This page allows users to see their connections, portfolio posts \& locations that have been previously visited.

\section{StudioGo Prototype Version One}
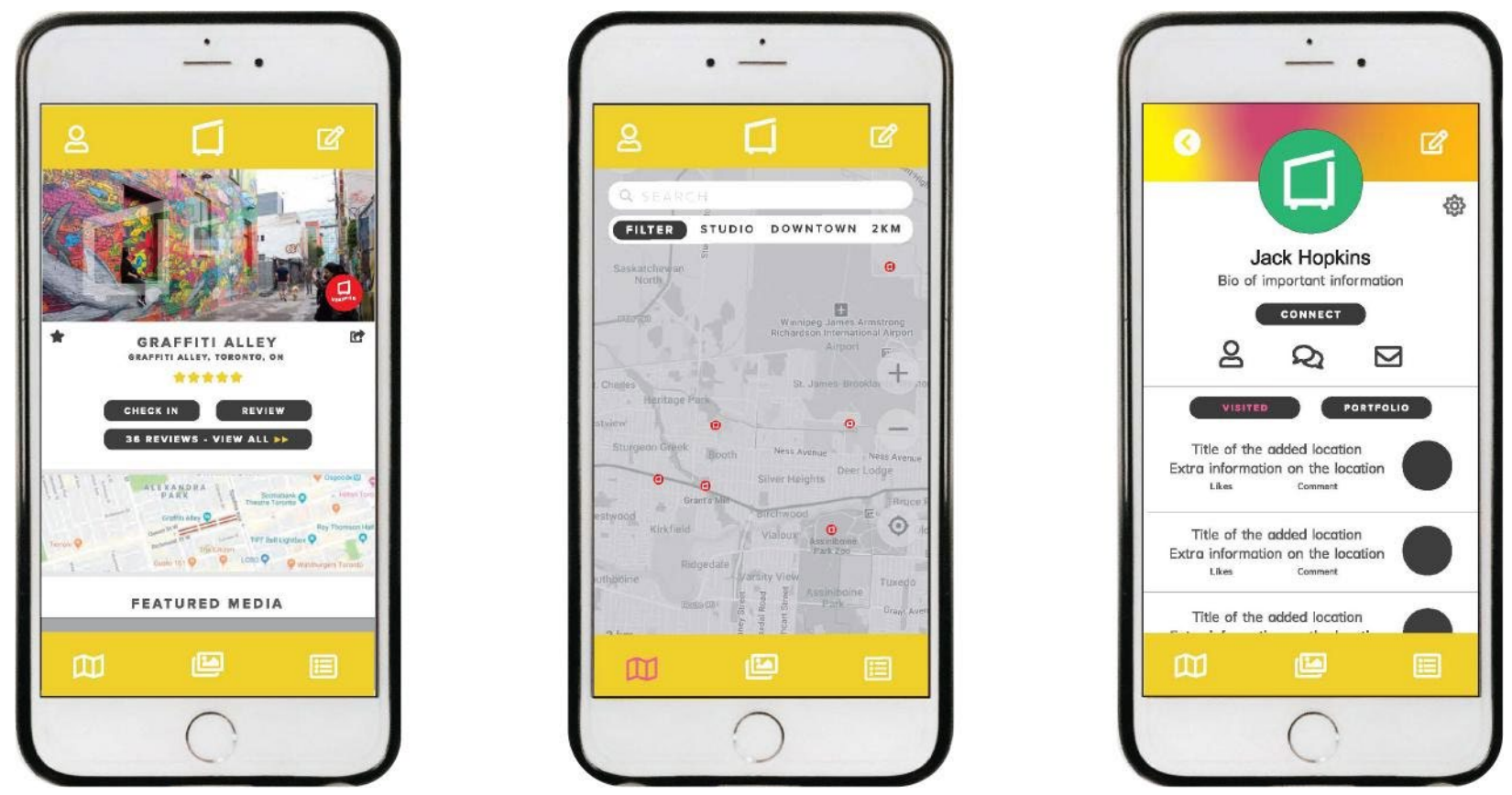

This is the first version of the StudioGo application. To get to this point StudioGo took interviews from the empathy phase, the fully realized problems in the define phase and the variety of ideas from the ideation phases to create a map-based peer-to-peer location scouter for creatives to find adequate and affordable workspaces all while connecting with those in their 
industry. This version of the application begins to show off many of the application's main features, which includes the main highlight, which is the home page map. This map shows all locations that are available in the user's local area, while the search and filter sections allow the user to narrow down those locations while tailoring the map to what their needs are. Once a location has been targeted the user will have the ability to view more information on that location on the location page. This gives the users information about this location that is tailored to creative needs, with the ability to check-in to the location or review it once you have been there. A profile page that allows users to post which locations they have visited \& post portfolio pieces is an area that allows users to connect through locations and their work. This is a feature that allows to application to become a community within all in one place.

\section{StudioGo Version One Test}

This version of the application did not last long. There were too many issues including the simplicity for the average user as it was too tailored to those in the creative field. We brought this version of the application to the user to do some testing on. Users provided information that allowed us to take a step in the right direction and change the prototype for the better. What did users like about our current rendition of the application? StudioGo users were impressed with the main map page, the ability to see information of a location more in depth than other applications, the ability to post their work \& tailor searches to what they want. With these positives also come some drawbacks to the design. The signifiers on the lower navigation bar such as the media button confused many of our users. The icons used on this navigation bar were not universally known to the average user, which rendered them useless during the test. Users also cited cluttered pages such as the (4) list view (which can be viewed in the Adobe XD link) which lists locations based on distance as an alternative to the main map page. With this information users 
gave their insights on how they would change the user interface. Users stated: "There may be too many features overall, simplifying the application would be my recommendation" (Interview 10, 2018). Another user gave some advice on the (5) media area, which in this version of the application is a way to see users work all in one area. This user believes that the section of the application was a bit too confusing and needed to be updated (Interview 8, 2018). Taking all this information into account StudioGo was able to come up with a new version of this application that satisfied many of the users needs.

\section{StudioGo Prototype Version Two}

After taking the time to learn about what the user wanted to see change from our previous version of the application, StudioGo designed a new and simplified version while keeping many of the main features and eliminating those which many users did not think were necessary. Keeping in mind the importance of bridging the average user and our target audience we needed to make sure this application was simple and intuitive enough to allow users to quickly and efficiently find the locations they need.

In the second version of the application we decided to overhaul both navigation bars. Beginning with the lower navigation bar. Our map page icon had been changed to a location pin. The reason for this was the universal understanding that this is a location drop pin, which is what the users will be searching for when looking for locations on our in app map. Our media button changed as well, to the universal play button. We decided to change these two items so users wouldn't feel isolated and confused by our application compared to many of the top brands already out in the marketplace. Our list view icon is now located on the top right-hand side of the map itself. This allows for seamless change between the two views so users can navigate 

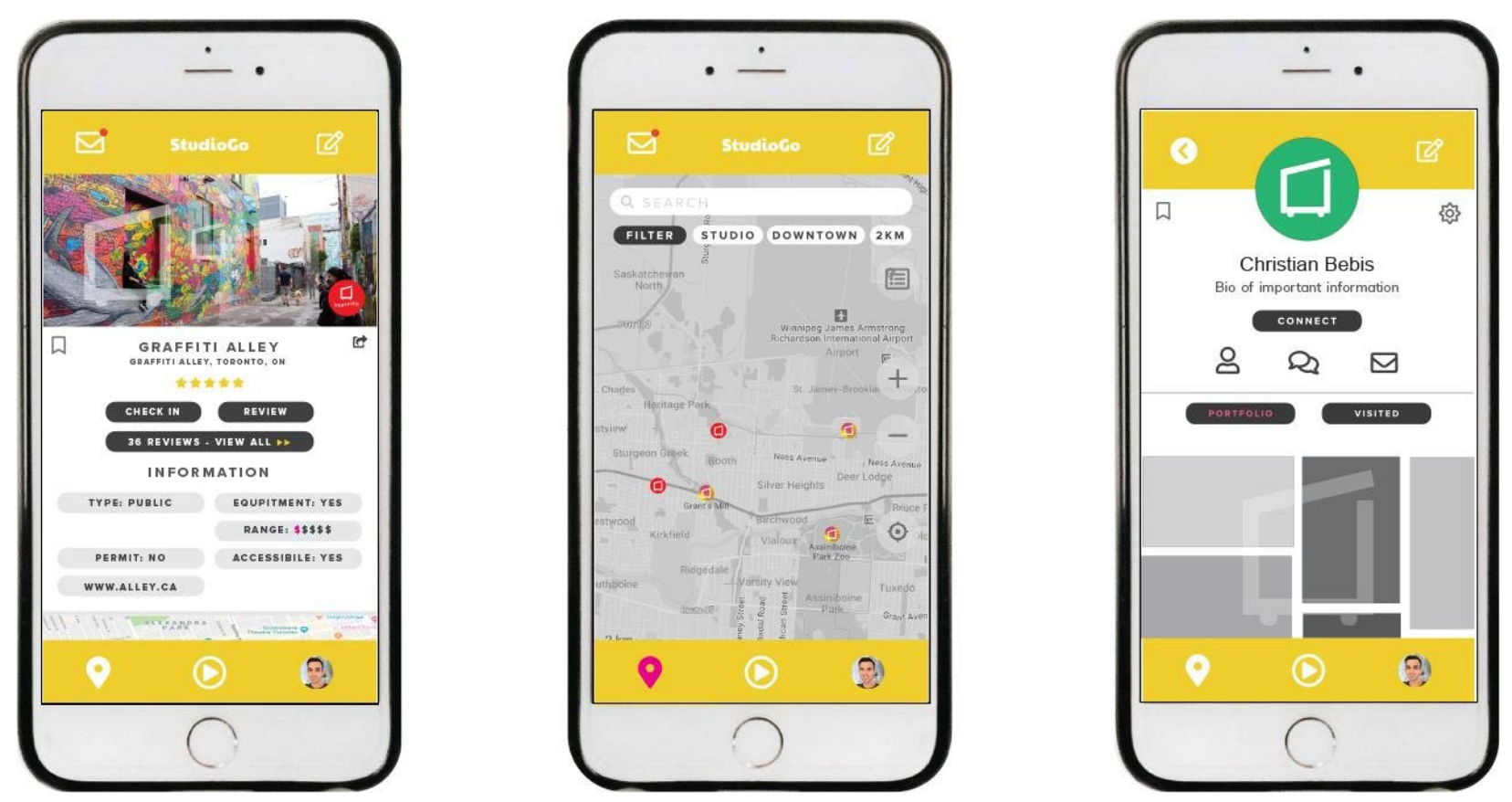

much more efficiently. Our profile page icon has moved from the top left corner to the bottom right. This was changed to see how users would react as we received mixed reactions on the button in the first version of the interface. As discussed previously with the ability to find adequate workspaces users wanted the ability to make connections with others in their field. The ability to have messages in the top left corner of all main page, as well as the profile page was a big part in allowing users to communicate with each other while finding these workspaces.

\section{StudioGo Version Two Test}

These were changes that we made based on user comments and concerns. We took this version to the user and once again discussed what they were happy with and also believed what needed to be changed. Interviews during this period were very positive. Users were very receptive to changes we had made. Citing one user who believed "I can understand the buttons much better than the first one" (Interview 14, 2019). Other users believed it was good, but not what they liked specifically saying "I like having all my main icons at the bottom, so I can get to them easier" (Interview 18, 2019). Comments like these allowed us to understand that we almost 
had the version of the application that we wanted. With a few tweaks we could get to the functionality level that we believe would allow users the greatest ability to find workspaces with a level of ease which they had not experienced in the past.

\section{StudioGo Version Three Prototype}

Version three of the StudioGo user interface is the first time in which StudioGo felt comfortable taking the User Interface into a working beta. After two rounds of user testing, it was understood that this version of StudioGo gives users the best ability to find adequate workspaces at a touch of a button in a peer-based community. A few changes were made from the previous versions of the application, but all core features were kept intact. The user interviews allowed StudioGo to understand the importance of the users throughout the development process and had a positive impact on the development of the StudioGo interface.
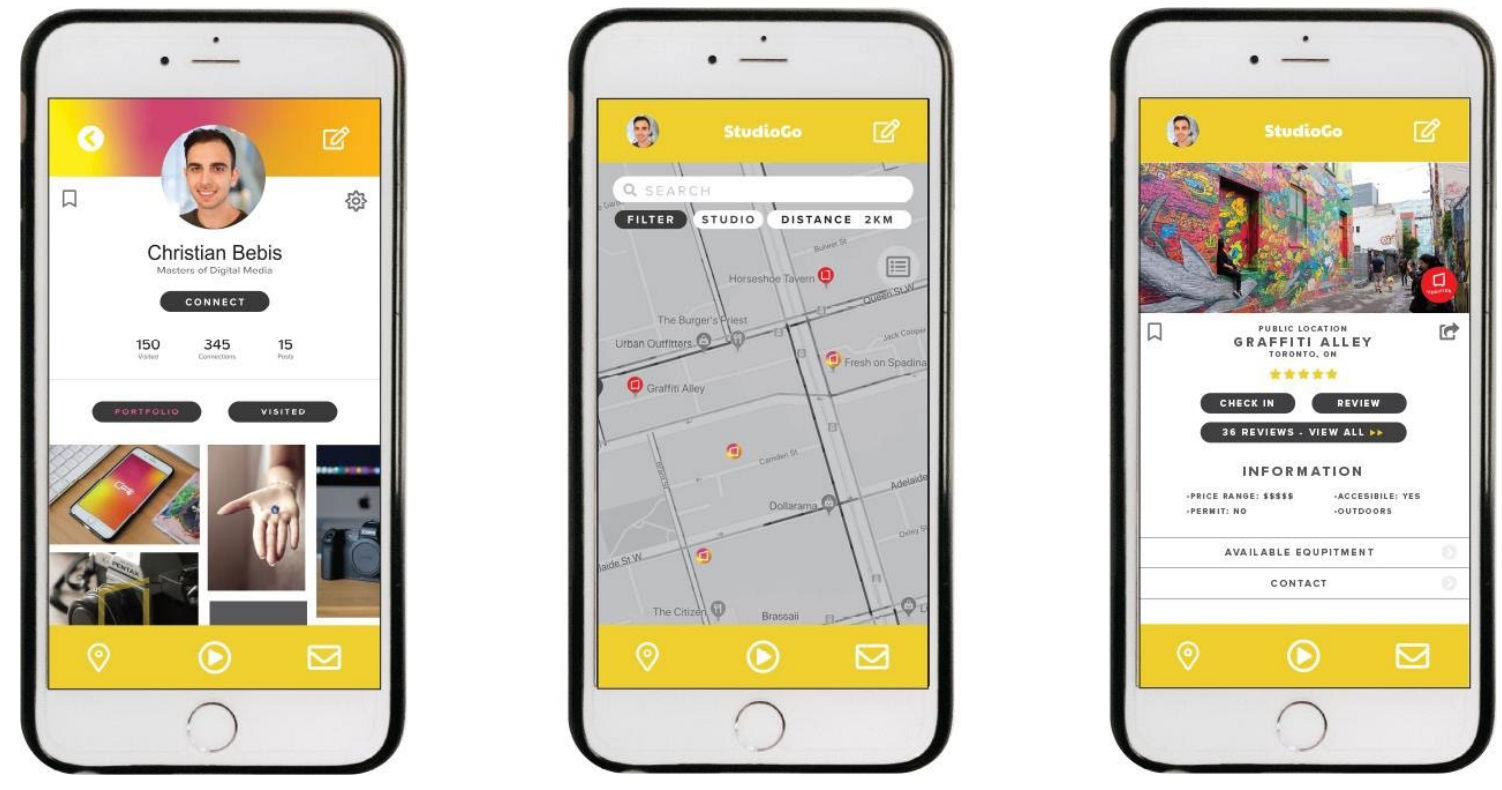

A few changes were made when considering this version of the user interface. The profile page icon was moved back to the top left corner to allow all major functions to be displayed on the bottom navigation bar. This includes the map pin icon, the media icon \& the (6) messaging 
system. (Once again you can see how these pages interact via our Adobe XD link). Along with this was a major overhaul of the profile page and location information page. The profile page was simplified to remove features that weren't necessary or duplicated on the below navigation bar. The portfolio section of the profile page was brought to the forefront to allow users to see work when they immediately land on a user's profile. The location page changed by adding more tailored information about a particular location including accessibility information, available equipment, whether the location is outdoors or needs a permit, and the cost. The most interesting feature that was added includes the type of space. This was added after reading Thoring's paper on creative workspaces. This allows the user the ability to know whether the space is a personal, collaborative, presentation, making or intermission space. These types of spaces will have the ability to be filtered in the search area of the application. Overall this is a much more simplified version of the StudioGo application, which will be continued to be worked on and changed once in the beta stage. Users will have the ability to actually use the application and give feedback so that StudioGo can continue to work towards the ultimate goal, which is to help creatives find adequate and affordable workspaces while connecting with their peers.

\section{StudioGo Version Three Test}

The third version of the application may have been the most successful in regards to feedback from our users. The application seemed to be coming together in ways it had not previously had. Users were excited about a variety of changes that were made in the user interface, which included button locations, new pages \& ease of functionality. During this test users were asked to carry out simple tasks. Task such as "locate the map page" and "add a location to the map" were carried out with ease by a majority of the users. Some users did have some recommendations for the application though. One user recommendation to see if a location 
is currently being used "I would want a feature to know the current availability to public locations, because you wouldn't want to go somewhere and have it be completely full with no room to work on your project" (Interview 19, 2019). With these recommendations came some changes to a few of the current pages. Users wanted to see more tailored information on creative locations when looking for a place to work. These were changes that needed to be done and would be added to the final prototype of the application.

\section{StudioGo Version Four Prototype (Final Prototype)}

The fourth version of the prototype is not quite a revamp, but a change in the way information is provided to the user in certain sections of the application. The sections of the user interface that got major overhauls include the (1) location information page, (2) location addition page, and the (3) location preview banner (which can all be seen below). This includes what the users see when adding or searching for a particular location by providing users with even more depth when using StudioGo.
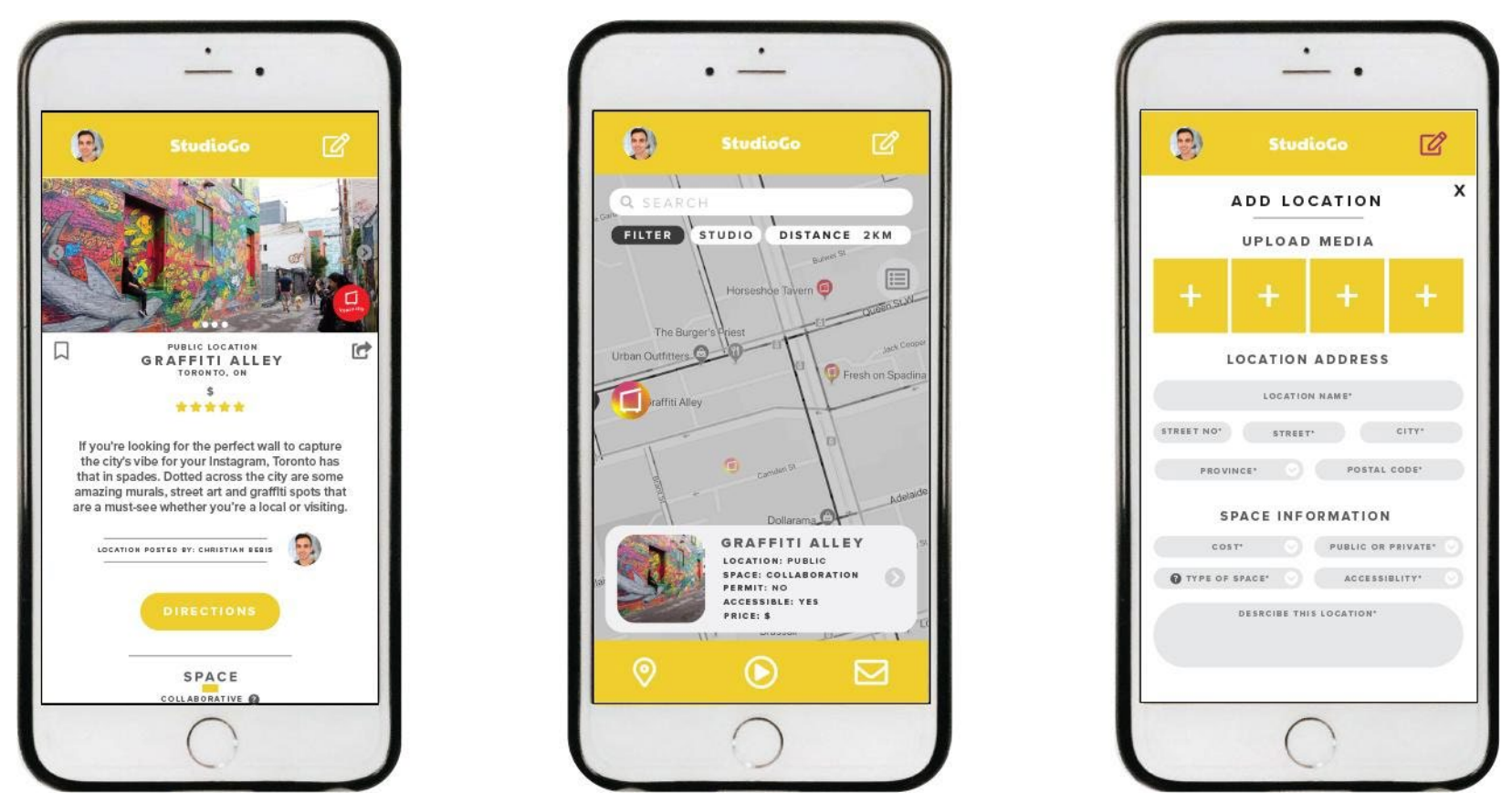

This is the most important update for the StudioGo user interface as it completely changes the 
information that StudioGo users will be looking for when attempting to find a location that suits them best. The Katja Thoring journal provided a fantastic description of a variety of creative spaces. StudioGo was able to take this information and use it as a main feature in the organization of spaces. This includes (1) The personal spaces that allows for a solo concentrated workflow; (2) Collaboration space, which is used for group projects; (3) presentation space, which is used to share ideas; (4) Making space, which could be considered another variation of the collaboration space, but with the tools to help creatives build and experiment, and (5) a space to get away from your work. With this information users can now filter and search for spaces based on the type of creative space, the type of equipment available at the space (cameras, tripods, printers, etc...), whether the space is public or private $\&$ how accessible the space is for the user. StudioGo needed to find a way to tailor the spaces to the creative community and by providing information that other services do not include, while also being an application that offers a peer-to-peer system to find and learn about new locations for creative work. With these changes it is the belief that this prototype can offer valuable information to the user that can help with their own creative endeavours.

\section{Conclusion}

Throughout this paper and the design process the Stanford design thinking model proved to be a helpful resource in the careful planning and execution of the solution. StudioGo was an idea that came to be through as a result of user interviews and insights. We were able to find a problem that many creatives faced and devise a solution that could help them in their search for creative workspaces. The empathize period allowed an understanding of the end users needs and importance. We learnt that it is important when building a product to listen to the people who are going to use it. Further understanding the user's personality, preferences and requirements in 
depth was a key factor. We learnt that defining the users problem into a design statement is a delicate task. The designer needs to take into consideration a variety of items which were discussed and condense it into a workable solution. From this point on it was important to create something that would solve problems for the user. StudioGo needed to create an accessible way for a user to find these workspaces. Building a user interface through user testing proved to be an incredibly useful task. This process helped shape the user interface to what it is today and will continue to grow with the help of a variety of users. After testing with users, in conclusion; StudioGo seems to be an essential tool in helping users finding creative spaces that will help them get back to work and expand their network.

Design thinking plays a critical role in devising a suitable product for the concerned user. User centered design process starts with a user in mind, stays synced with the user while progressing through its stages and comes back full circle to incorporate feedback of its user. This iteration cycle continues until a digital product remains alive. 


\section{References}

Allahbakhsh, M., Benatallah, B., Ignjatovic, A., Motahari-Nezhad, H. R., Bertino, E., Dustdar, S. (2013). Quality Control in Crowdsourcing Systems: Issues and Directions. IEEE Internet Computing, 17, (2), 76-81. Washington: IEEE Computer Society.

Davis, J. G., Rahmanian, B. (2014). User Interface Design for Crowdsourcing Systems. Proceedings of the Workshop on Advanced Visual Interfaces AVI. New York: ACM.

Howe, J. (2006). The Rise of Crowdsourcing. Wired Magazine, 14, 1-6. San Francisco: Conde Nast Publications.

Krishna, G., (2015). The best interface is no interface. New Jersey: Pearson.

Krug, S., (2014). Don't make me think. New Jersey: Peason.

Komarov, S., Reinecke, K., Gajos, K. Z. (2013). Crowdsourcing performance evaluations of user interfaces. In Proceedings of the SIGCHI Conference on Human Factors in Computing Systems.

Norman, D. A. (2013). The design of everyday things: Revised and expanded edition. New York: Doubleday.

Raz, A. (2017, February 21). Get Started with Design Thinking. Retrieved from https://dschool.stanford.edu/resources/getting-started-with-design-thinking

Ropo, Arja., Paoli, D.D., (2017). Creative workspaces - a fad or making real impact? Journal of Corporate Real Estate, 19 (3), 157-167.

Thoring, K., Desmet, P., Schaub, P. B., (2018). Creative environments for design education and practice: A typology of creative spaces. Design Studies, 56, 54-83.

WeWork. Office Space and Workspace Solutions. Retrieved from https://www.wework.com/ Interview 10 (2018). Personal Interview.

Interview 8 (2018). Personal Interview.

Interview 14 (2019). Personal Interview.

Interview 18 (2019). Personal Interview.

Interview 19 (2019). Personal Interview.

Bebis, C., Hopkins, J. (2019). StudioGo (1.0). [Mobile Application Software] Prototype

Retrieved from $<$ https://xd.adobe.com/view/452cae45-b385-4053-40a4-4553f1441a51$\underline{331 \mathrm{~d} />}$ 
Bebis, C., Hopkins, J. (2019). StudioGo (2.0). [Mobile Application Software] Prototype Retrieved from $<$ https://xd.adobe.com/view/613f9288-7de3-4198-5524-11e0b2d3b2c8$\underline{170 \mathrm{e} />}$

Bebis, C., Hopkins, J. (2019). StudioGo (3.0). [Mobile Application Software] Prototype Retrieved from $<$ https://xd.adobe.com/view/f69aab17-e926-4307-6b3f-08b716e73f08$\underline{80 \mathrm{ab} / \text { ?fullscreen }>}$

Bebis, C., Hopkins, J. (2019). StudioGo (4.0). [Mobile Application Software] Prototype Retrieved from $<$ https://xd.adobe.com/view/9fbc7da0-06fb-4c9d-4a11-5a87953f58d2$\underline{\text { e98d/?fullscreen }>}$

Figure 1. The Stanford Design Thinking Model. Adapted from the Institute of Design at Stanford University. designed by Bebis, C. (2019).

Figure 2. Pie Chart on statistics from Problems \& Pains Creatives Believe They Suffer. Adapted from 'StudioGo's Research on Creatives' by Bebis. C and Hopkins. J. (2019). 